\title{
O corte a laser na marchetaria em couro: o processo de design com reaproveitamento dos rejeitos
}

Laser cutting in marquetry leather: the design process with reuse of waste

\section{Stella Lisboa Sapper}

Mestre em Design pela Universidade Federal do Rio Grande do Sul stellasapper@gmail.com

\section{Uda Flavia Cunha Souza Fialho}




\section{O corte a laser na marchetaria em couro: o processo de design com reaproveitamento dos rejeitos}

Laser cutting in marquetry leather: the design process with reuse of waste

\section{Stella Lisboa Sapper e Uda Flavia Cunha Souza Fialho}

\section{Resumo}

O objetivo deste trabalho foi apresentar o processo de marchetaria, com a utilização da tecnologia de corte a laser, aplicado em rejeitos de couro para o desenvolvimento de produtos de design de moda. Este trabalho foi desenvolvido a partir do estudo de caso da marca Brantê, cujos dados foram coletados por meio de observação e entrevistas informais. Ao final do estudo, constatou-se que a marchetaria em couro com utilização de corte a laser é um processo passível de ser aplicado em diversos tipos de produtos; também se percebeu que os produtos desenvolvidos pela Brantê obtêm destaque no mercado por apresentarem valor estético e simbólico resultantes de um processo de design diferenciado. $\mathrm{O}$ reaproveitamento do couro contribui, ainda, para o resultado alcançado pela empresa no mercado, uma vez que o processo é adequado aos padrões dos produtos, obedecendo a critérios de qualidade para o reaproveitamento de um material descartado anteriormente.

Palavras- chave: Rejeitos de couro. Tecnologia de corte a laser. Produtos de moda.

\begin{abstract}
The objective of this study was to present the marquetry process, with the use of laser cutting technology, applied to leather waste to develop fashion design products. This work was developed from the case study of Brantê brand, whose data were collected through observation and informal interviews. At the end of the study, it was found that the marquetry leather with the use of laser cutting is a process that can be applied to various kinds of products; also it realized that the products developed by Brantê get prominence in the market because they have aesthetic and symbolic value resultant of a distinctive design process. The reuse of leather also contributes to the result achieved by the company in the market, once the process is suitable to the standards of the products developed, according to quality criteria for reuse of a material discarded earlier.
\end{abstract}

Keywords: Leather Waste. Laser cutting technology. Fashion products.. 


\section{Introdução}

O couro é um material produzido a partir de peles de animais e passa por um processo de curtimento para se tornar utilizável e passível de aplicação em produtos. Suas características dependem, tanto da origem do animal possuidor da pele, quanto do tipo de processo de curtimento. Tais variações possibilitam a elaboração de couros com características distintas e que, por isso, podem ser aplicadas em diversos tipos de produtos. O processo de curtimento do couro é composto por várias etapas em que cada uma gera resíduos com diferentes características.

O couro pronto para comercialização passa por um processo de seleção de materiais realizado pelas indústrias que o utilizam como matéria-prima dos seus produtos. No processo da compra, os compradores rejeitam uma porcentagem de material, e este passa a ser negociado por um preço mais baixo que o valor de mercado. As aparas do couro rejeitado tornam-se matérias-primas para processos de fabricação de novos produtos, tais como recouro, tijolo a frio, entre outros, podendo ser aproveitadas de diversas formas. Qualquer reutilização apresenta mais vantagens do que desvantagens, já que a destinação atual mais comum dos resíduos são os aterros sanitários (VAZ et al., 2009).

O resíduo é considerado lixo, pois não possui valor comercial ou utilidade, ocasionando problemas para o meio ambiente, visto que, em geral, é subutilizado ou descartado indevidamente (LIMA; SILVA, 2005 apud RASEIRA, 2013). O rejeito, por sua vez, tem valor comercial, podendo ser utilizado e aplicado no desenvolvimento de novos produtos. No entanto, se o rejeito não for utilizado pode se tornar um resíduo e também acarretar problemas para o meio ambiente. O rejeito do couro é utilizado como matéria-prima essencial dos produtos desenvolvidos pela Brantê - estudo de caso deste artigo.

Manzini e Vezzoli (2008) destacam que o papel do Design pode ser sintetizado como a atividade que, ligando o tecnicamente possível com o ecologicamente necessário, faz nascer novas propostas que sejam social e culturalmente apreciáveis. Seguindo os princípios dos 3R's, mais especificamente o princípio do terceiro $\mathrm{R}$ - que diz respeito à reutilização - a Brantê reaproveita o material descartado para desenvolver produtos em couro a partir da técnica de marchetaria. A empresa também utiliza o corte a laser no processo de produção dos produtos, com o intuito de obter o êxito esperado nos resultados. 
O objetivo deste estudo é apresentar o processo de marchetaria em couro com a utilização da tecnologia de corte a laser aplicado a rejeitos de couro para o desenvolvimento de produtos de design de moda, utilizando a marca Brantê e seu processo produtivo como estudo de caso.

\section{COURO}

O couro é um material proveniente da pele animal que passa por um processo de curtimento, para modificar as fibras de sua estrutura com auxílio de produtos químicos naturais ou sintéticos - curtentes (NBR 10.004 ABNT, 2004). A pele animal apresenta variações, tanto pelo tipo de animal do qual foi originada (bovino, suíno, caprino, ovino, e outros animais exóticos), quanto pelo clima, alimentação e outros aspectos. O objetivo do processo de curtimento é transformar a pele animal - caracterizada como putrescível, sem resistência mecânica, resistência térmica e sem uniformidade - em um material resistente, durável e passível de aplicação em diversos tipos de artefatos, denominado de couro (STÜRMER, 2010).

O mais importante constituinte do couro é o colágeno da pele, substância protetora das fibras brancas do tecido conjuntivo. Um exame atento à composição de um pedaço de pele mostra que consiste principalmente de fibras grossas longas e feixes de fibras entrelaçadas em três dimensões, fato que confere aos materiais feitos de pele muitas de suas qualidades físicas únicas (SUDHA et al., 2009). Trata-se de um material constituído essencialmente por derme que contém propriedades únicas e características bastante variadas.

A qualidade dos couros depende de uma série de fatores. Os cuidados iniciam-se durante a criação dos rebanhos por meio do controle de parasitas e formas adequadas de identificação, condução, confinamento e transporte dos animais. A partir do seu abate, deve-se evitar que suas peles sejam degradadas pela ação de microorganismos, para que seu processamento seja eficiente e origine couros de boa qualidade. Ou seja, a qualidade do couro depende do manuseio, da conservação e do armazenamento adequados das peles (PACHECO, 2005).

Como um material que possui qualidades diversificadas, o couro diferencia-se também em termos de conforto para o usuário. O material poroso permite a respiração da pele e, sendo permeável à transpiração, proporciona conforto na sua utilização; também é elástico, flexível, resistente à flexão, à tração e ao atrito. Segundo Gutterres e 
Osório (2004), o homem prefere o uso do couro, devido ao conforto proporcionado, às boas propriedades fisiológicas e a sua flexibilidade. Dessa forma, tais aspectos possibilitam sua aplicação como matéria-prima em produtos de vários segmentos, como indústria automobilística, esportes, mobiliário, indústria do lazer, vestuário, calçado e setor rural (CAMPOS, 2006).

Segundo Campos (2006), o Brasil é um dos maiores produtores e exportadores de couro, com um expressivo mercado interno que se desenvolve em diversos polos produtores regionais, com diferentes condições econômicas, históricas e culturais. O Ministério do Desenvolvimento, Indústria e Comércio Exterior Brasileiro aponta o Brasil como um país que tem oportunidade de ser um dos principais fornecedores mundiais de couro acabado, haja vista o tamanho de seu rebanho bovino e a disponibilidade de espaço para a criação de gado. O país apresenta condição de explorar a demanda de couro para móveis e estofamentos de automóveis, como também para sapatos de maior valor agregado.

\subsection{Rejeitos de couro}

Da mesma forma que a indústria do couro traz benefícios à sociedade, movimentando a economia do país, causa danos consideráveis ao meio ambiente (HU et al., 2011). O processo de curtimento de couro produz resíduos sólidos, líquidos e gasosos que variam de acordo com suas etapas: são resíduos com grandes cargas orgânica e inorgânica, e cromo - utilizado durante o processo de curtimento (CASTILHOS; TEDESCO; VIDOR, 2002). Os resíduos de curtume apresentam alto risco de contaminação ambiental e têm como destino final mais comum os depósitos ou aterros sanitários (COSTA et al., 2001).

O processo de curtimento do couro é composto por várias etapas e cada uma gera resíduos com diferentes características. De acordo com a NBR 10.004 (ABNT, 2004), o processo de caracterização de um resíduo sólido identifica se este deve ser qualificado como perigoso por apresentar características de inflamabilidade, corrosividade, reatividade, toxicidade e patogenicidade. Tais características devem nortear os cuidados no gerenciamento do resíduo sólido. A classificação divide os resíduos em: classe I (perigosos), classe II (não-perigosos); classe IIA (não inertes) e classe IIB (inertes). 
Matos et al. (1999) observam que sobras pós-uso ou consumo de produtos industrializados, incluindo os de classe II (não perigosos), têm decomposição lenta que varia de 1 mês a 4.000 anos e, dessa forma, podem alterar as propriedades do meio ambiente e provocar impacto ambiental. Segundo Lago (2007), o cromo é vantajoso para o processamento industrial da pele, contudo, se exposto à luz, ao oxigênio e ao calor, é convertido em cromo 6, considerado carcinógeno; após essa transformação, a substância pode infiltrar-se na terra, contaminando água e alimentos.

Além dos danos ambientais causados a partir do processo de curtimento, o descarte do couro é outro problema que traz consequências ao meio ambiente. $\mathrm{O}$ couro finalizado para a venda, pronto para aplicação em diversos tipos de produtos, também pode ser descartado na hora da compra pelas grandes indústrias. O couro é disposto em grandes peças (Figura 01), e o descarte acontece durante a etapa de seleção de materiais que as empresas fazem no momento da compra: observam a peça e adquirem apenas a parte que atende aos seus critérios de qualidade.

Figura 01 - Grandes peças de couro prontas para a venda

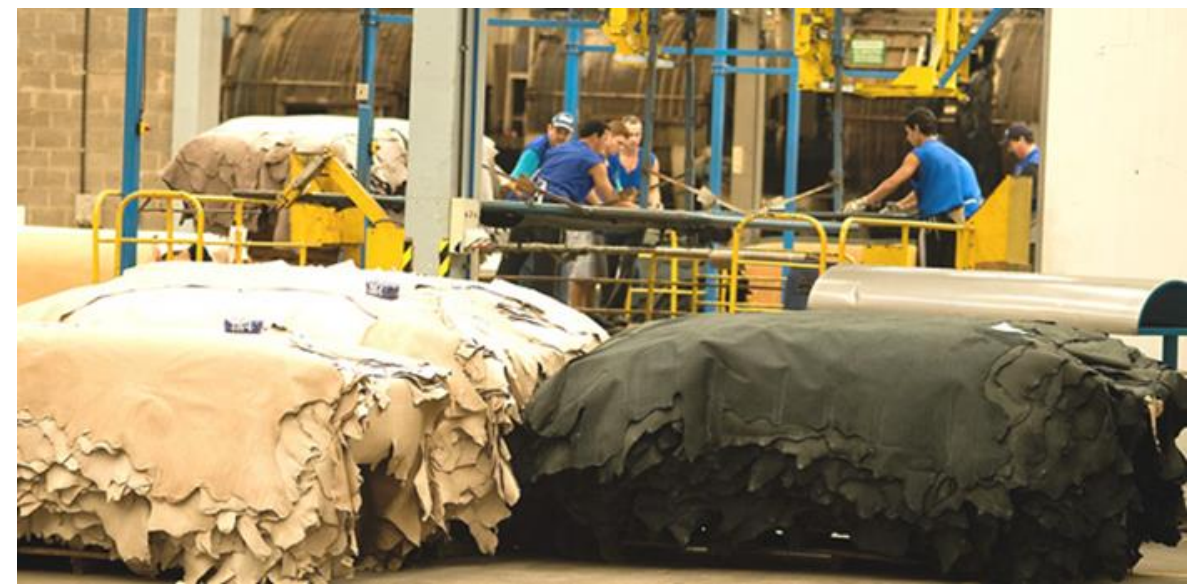

Fonte: www.al couro.com.br

A peça descartada é denominada de rejeito e constitui, comumente, uma pequena fração de uma grande peça do couro. No entanto, o rejeito ainda é descartado, numa proporção suficientemente extensa, para ser aplicada em muitos tipos de produtos. Além disso, o rejeito de couro é comercializado a um custo bem abaixo em relação ao couro vendido no mercado. Esse tipo de material é a matéria-prima utilizada na Brantê o estudo de caso deste artigo.

O termo reutilizar pode ser definido como sendo um "segundo uso de produtos, 
ou de suas partes, previamente descartados e eliminados" (MANZINI; VEZZOLI, 2008). O reaproveitamento do couro rejeitado pode ser encaixado nos princípios da política dos 3R's (reduzir, reciclar, reutilizar), dentro do princípio Reutilizar. Além de possibilitar a sua reutilização como um material descartado, o rejeito de couro é de baixo custo e possibilita a criação de vários produtos, com aplicação nos mais diversos setores.

O design age como principal ferramenta no processo de criação dos produtos da marca estudada, possibilitando a utilização da tecnologia de corte a laser, para aprimorar a técnica de marchetaria e, ao mesmo tempo, aplicando-a no couro para o desenvolvimento de produtos pertencentes à grande área da moda. O design tem-se constituído num efetivo elemento diferenciador no segmento de couros acabados para diversos usos. As tendências recentes mostram, inclusive, o desenvolvimento de design em couros como uma nova forma de acrescentar valor ao produto final (CAMPOS, 2006).

\section{PROCESSO DE MARCHETARIA}

A palavra marchetaria origina-se do termo francês marqueter que significa embutir ou incrustar. A marchetaria é a arte, ou técnica de ornamentação, utilizada para produzir desenhos decorativos em superfícies através do uso de facetas finas de madeira e outros materiais, como os metais, materiais gemológicos, madrepérola, plásticos, marfim, chifres de animais, etc. As diferentes cores e texturas enaltecem o material utilizado por meio do contraste na formação dos desenhos (GILBERT; LÓPEZ; ORDOÑEZ, 2000 apud RASEIRA, 2013).

As origens da marchetaria são incertas, porém hieróglifos e pinturas indicam que folheados de madeira foram cortados com lascas de bronze e aplicados em caixões no antigo Egito. Na mesma época, com a disseminação da arte dos mosaicos, não demorou muito para que os artesãos experimentassem criar desenhos formados a partir de diferentes facetas. No século XIV, a marchetaria se desenvolveu no norte da Itália como um método de decoração das catedrais, enquanto, nos séculos seguintes, surgiram também escolas na França, Alemanha e Holanda. Entre os séculos XVI e XVIII foram produzidos muitos trabalhos primorosos para a decoração de móveis. Hoje existem alguns profissionais especializados em marchetaria, porém são os amadores que produzem grande parte dos melhores trabalhos (SMITH, 2002). 
Sendo irrestrita comercialmente, a marchetaria está frequentemente se renovando através de novas técnicas desenvolvidas pelos profissionais, artesãos e amadores que a utilizam (SMITH, 2002). Atualmente, o processo mais utilizado de marchetaria associa diferentes lâminas de madeira num mesmo plano para compor um desenho, gerando uma superfície lisa que será, posteriormente, colada a um mobiliário ou a elemento decorativo (GILBERT; LÓPEZ; ORDOÑEZ, 2000 apud RASEIRA, 2013).

\subsection{Corte a laser aplicado à marchetaria}

O laser (Light Amplified by Stimulated Emission Radiation) possui uma extensa aplicabilidade em diversas áreas de pesquisa. Seu funcionamento é baseado nas leis fundamentais da interação da radiação luminosa com a matéria (BAGNATO, 2008 apud STÜRMER, 2010). Para Thompson (2011 apud CIDADE, 2012), o laser é uma das maiores inovações do século XX, principalmente pela gama de possibilidades e aplicações que essa tecnologia permite.

Ao ser utilizado como instrumento de corte, o laser vaporiza o material no local do corte, removendo automaticamente o subproduto, sem deixar vestígios. Isso faz com que o corte seja mais preciso do que quando é obtido por outros meios. Um corte feito com laser normalmente apresenta bordas mais limpas do que um corte feito, por exemplo, por brocas convencionais (STÜRMER, 2010). Han et al. (2005 apud RASEIRA, 2013) acrescentam que a utilização do laser pode assegurar condições necessárias para aumentar a qualidade das peças trabalhadas e a taxa de produção.

Para cada aplicação existe um tipo de laser. A combinação entre o tipo de laser, sua potência e comprimento de onda são pontos de grande importância durante o desenvolvimento de um determinado produto. Logo, o laser deve estar de acordo com o material a ser processado (BAGNATO, 2008 apud STÜRMER, 2010).

A necessidade de se manter em um mercado competitivo e a exigência por produtos de qualidade em um prazo curto de tempo faz com que a indústria esteja investindo bastante na tecnologia de corte a laser. Isso está ocorrendo devido à agilidade que a tecnologia permite e o consequente aumento na produtividade (BARTZ et al., 2011).

O couro é um material que responde bem ao processo de corte a laser. É possível prever cortes e gravações na superfície do couro natural com certa facilidade, porém os 
parâmetros variam de acordo com o tipo de acabamento da superfície, ou flor, e a espessura do couro. Os couros acabados com pinturas e graxas dificultam o processo de corte, tanto em baixa como em alta velocidade, uma vez que o acabamento do corte fica comprometido, com chamuscados, enrugamentos e repuxe. Para esse tipo de couro, o corte deve ser feito do lado do avesso, ou carnal, o que permite que se obtenha bons resultados de acabamento (STÜRMER, 2010).

Outra técnica utilizada, para melhorar o acabamento do corte a laser em couro, é a umidificação. Durante esse processo, utiliza-se a água como agente refrigerante, evitando pontos chamuscados e repuxes no corte. O couro a ser cortado deve ser umedecido em água e, logo após, ser submetido ao corte com laser. Esse processo permite que mais tipos de couro possam ser submetidos ao corte a laser com bons resultados de acabamento (STÜRMER, 2010).

\section{MATERIAIS E MÉTODOS}

Este estudo foi realizado por meio de uma revisão bibliográfica para fundamentar o processo de produção da empresa analisada como estudo de caso - a Brantê. Simultaneamente, foi feita uma pesquisa na Internet sobre a marca. A coleta de dados foi realizada através de acompanhamento do processo produtivo, com observação, entrevistas informais e documentação. $\mathrm{O}$ acompanhamento aconteceu no atelier da Brantê, onde a observação, com caráter participante, foi realizada juntamente com a entrevista informal, cujos dados coletados foram pontos importantes para o entendimento do processo. A documentação foi feita através de fotografias e anotações. Os dados coletados sobre o processo foram analisados de acordo com a fundamentação teórica realizada.

\section{ESTUDO DE CASO: BRANTÊ}

A Brantê é uma marca de acessórios e artefatos em couro, cujo atelier localizase na cidade de Porto Alegre, no Rio Grande do Sul. A marca originou-se em maio do ano de 2012 e, desde então, vem atuando no mercado, tanto no atacado quanto no varejo. Os acessórios da Brantê destacam-se, principalmente, pela diferenciação dos aspectos estéticos, resultado do processo de criação e desenvolvimento. As coleções da marca acompanham o atual calendário de moda do Brasil, e os produtos abrangem colares, braceletes e bolsas. Na coleção Outono/Inverno 2013, a Brantê desenvolveu um 
processo de marchetaria em couro, utilizando o corte a laser que, a partir de então, tornou-se o principal fator de distinção dos produtos da marca.

Para compreender o processo de desenvolvimento dos acessórios da marca, realizou-se o acompanhamento e a observação das atividades realizadas que abrangeu todo o processo de criação e o processo produtivo. Nesta seção, descrevem-se, primeiramente, os meteriais utilizados (Figura 02); em seguida, o processo de criação dos produtos (Figura 03) e, por fim, a sequência das atividades da cadeia de produção (Figura 07). O processo de criação e de produção da Brantê foram divididos em etapas.

\subsection{Materiais utilizados nos produtos}

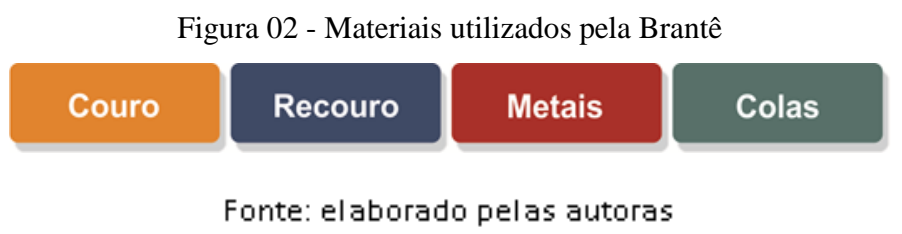

Couro: o couro utilizado pela marca é adquirido em Novo Hamburgo, no Rio Grande do Sul, em lojas que vendem os rejeitos da produção dos curtumes. Isso faz com que a marca faça um reaproveitamento de couros que já foram desenvolvidos e que foram rejeitados pela indústria na etapa de seleção de materiais. A metragem mínima para o desenvolvimento de um couro novo nos curtumes varia de 80 a 100 metros. Com o reaproveitamento dos rejeitos dos curtumes, a marca minimiza o risco de alto descarte na produção.

Recouro: o recouro, ou couro reconstituído, é geralmente composto por couro, resina e outros materiais. Ele é feito a partir de aparas, pó e resíduos de couro da indústria. $\mathrm{Na}$ Brantê, esse material é utilizado para proporcionar sustentação e estruturação de peças, sendo geralmente colocado entre duas camadas de couro natural.

Metais: os metais utilizados são de alta qualidade, feitos com a tecnologia PVD (Physical Vapour Deposition). A utilização desse tipo de metal é uma forma de proporcionar aos produtos acabamentos resistentes e duráveis; além disso, esses metais possibilitam maior versatilidade de cores.

Colas: as colas de contato e colas universais são utilizadas na montagem das peças. 


\subsection{Processo de criação e desenvolvimento da marchetaria em couro}

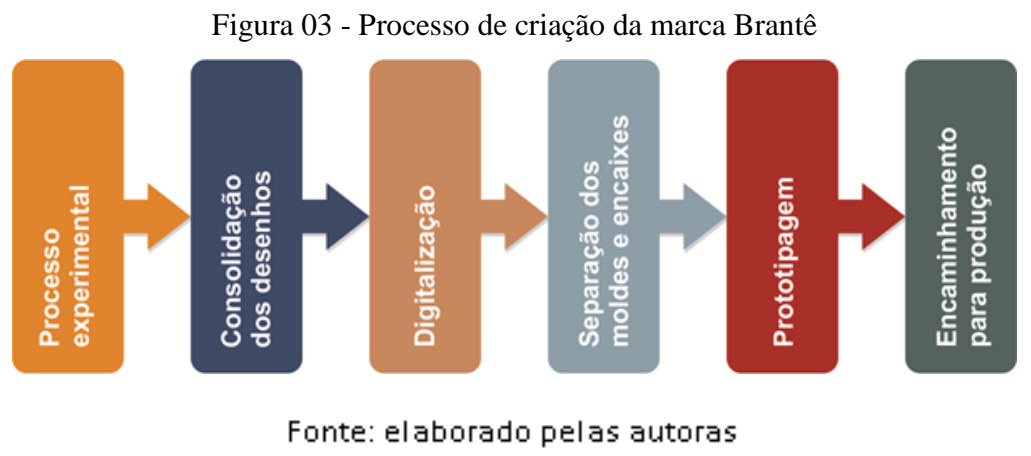

\section{$1^{\mathrm{a}}$ etapa $\mid$ Processo experimental}

Na primeira fase do processo criativo, utilizaram-se desenhos, recortes de couro, recortes de papel, fitas adesivas e diferentes metais que serviram de base para a criação (Figura 04). Os materiais passaram por experimentações de encaixes que dão origem a formas geométricas de diferentes padrões nas quais testa-se também a aplicação dos metais. Assim, o processo experimental resulta na materialização da identidade final das peças. 
Figura 04 - Início do processo criativo

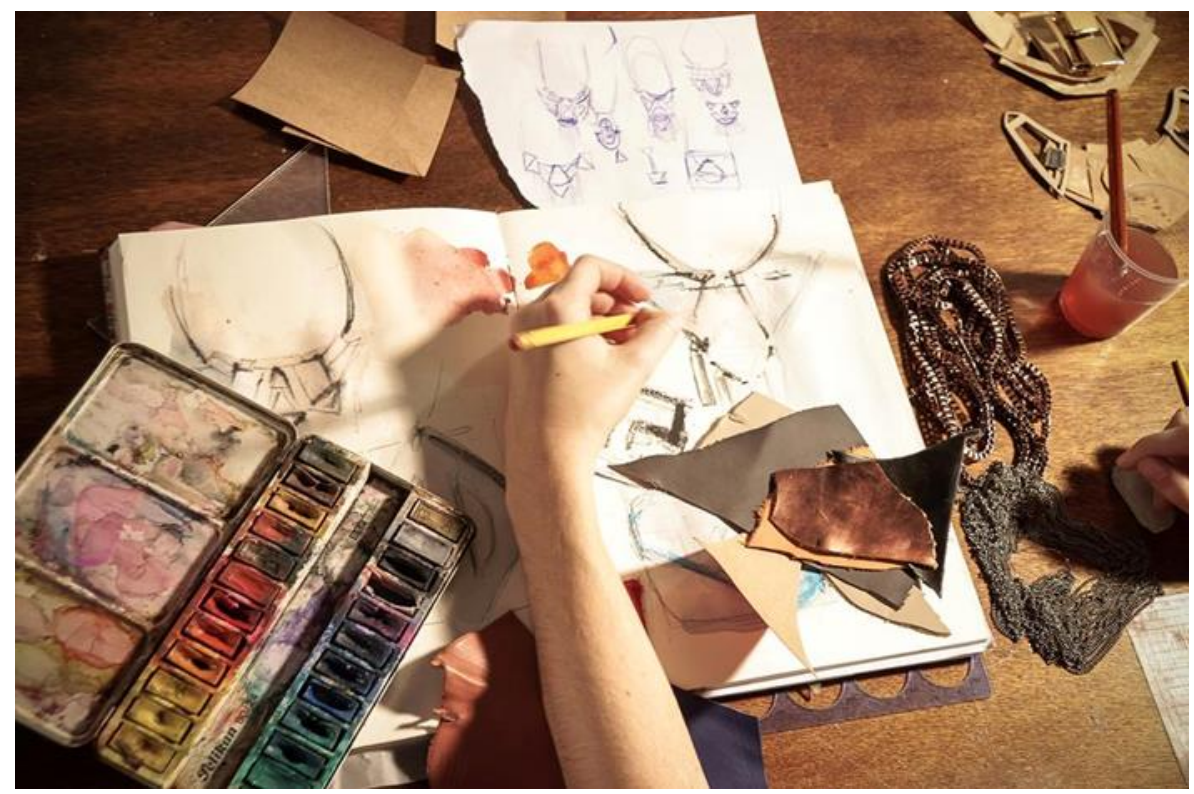

Fonte: material cedido pela marca Brantê

\section{$2^{\mathrm{a}}$ etapa | Consolidação dos desenhos}

Após o processo experimental, faz-se uma seleção das peças da nova coleção para serem redesenhadas com maior detalhamento. Nessa fase, os conceitos apresentam variações de cores e dos metais utilizados.

\section{$3^{\mathbf{a}}$ etapa | Digitalização}

Após a seleção das peças e do detalhamento dos conceitos, os desenhos a serem utlizados no processo de marchetaria são digitalizados, vetorizados e coloridos (Figura 05), facilitando o andamento do próximo passo - separação de moldes e encaixes. Nessa etapa de digitalização, são utilizados os softwares AutoCAD 2013 e Corel Draw X6. 


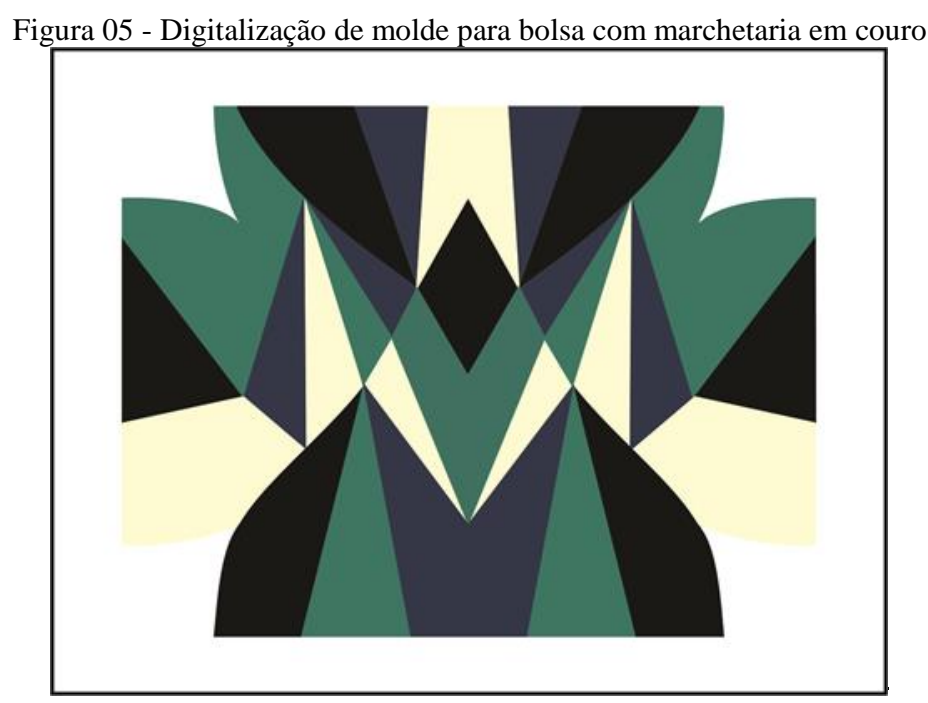

Fonte: material cedido pela marca Brantê

\section{$4^{\text {a }}$ etapa | Separação dos moldes e encaixes}

Nessa etapa, os moldes são separados conforme a cor e os encaixes previstos dentro de uma determinada área para o corte a laser (Figura 06). Desse modo, seguindo a lógica de disposição descrita, o corte minimiza o desperdício de material.

Figura 06 - Moldes e encaixes para montagem de marchetaria para bolsa
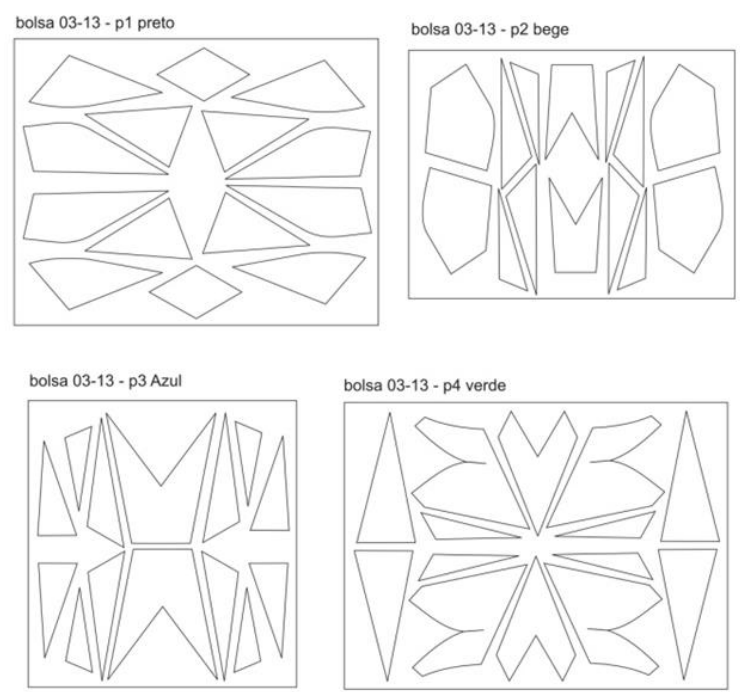

Fonte: material cedido pela marca Brantê 


\section{5 etapa | Prototipagem}

Nessa etapa, as peças são encaminhadas para a prototipagem, e os arquivos digitalizados passam pelos ajustes necessários.

\section{$6^{\mathbf{a}}$ etapa | Encaminhamento para a produção}

Após os arquivos terem sido ajustados conforme as necessidades apontadas na elaboração dos protótipos, as peças são encaminhadas para a produção, finalizando o processo de criação da marca Brantê.

\subsection{Cadeia de produção}

A cadeia de produção concentra-se na cidade de Porto Alegre e Novo Hamburgo, Rio Grande do Sul. Os serviços terceirizados são encarregados por grande parte da cadeia produtiva. $O$ atelier responsabiliza-se pela montagem final de aproximadamente $70 \%$ das peças, organização e envio para os compradores. Sendo assim, pode-se dividir a cadeia de produção de acordo com as tarefas, como mostra a Figura 07.

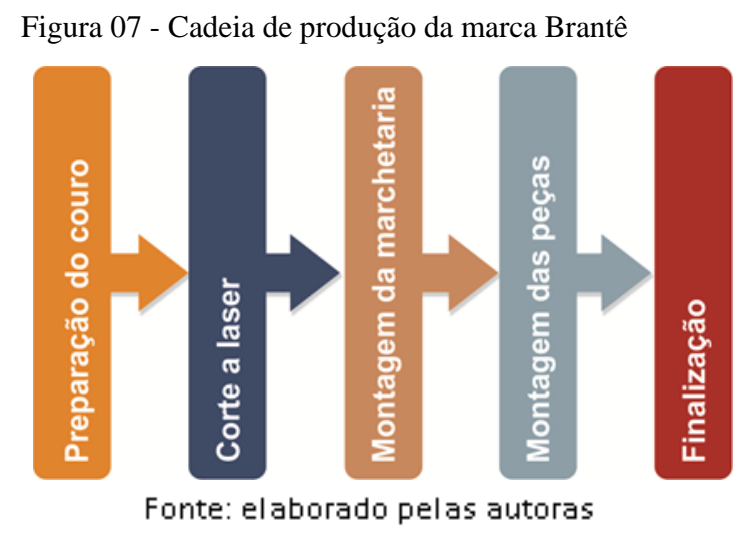

\section{$1^{\text {a }}$ etapa | Preparação do couro}

Os pedaços de couro comprados para a produção passam por um processo para redução da espessura, com o intuito de proporcionar maior maleabilidade ao couro, como também aprimorar os aspectos estéticos para a produção dos acessórios. Quando se trata de peças mais estruturadas, logo após a diminuição da espessura, o recouro é colado no lado do carnal do couro para aumentar a sustentação e facilitar o corte e os encaixes do processo de marchetaria. A área de couro prevista para os moldes é medida e cortada manualmente para o encaminhamento do corte a laser. 


\section{$2^{\mathrm{a}}$ etapa $\mid$ Corte a laser}

Os moldes são cortados a laser e separados de acordo com a cor e a referência. Após o corte, os moldes são limpos e conferidos. Para simular o corte a laser do processo, foram feitos testes em amostras de couro de $1 \mathrm{~mm}$ de espessura prontas para o corte, cedidas pela marca. Utilizou-se a máquina Yueming Laser CMA-1200 (Figura 08) que pertence ao Laboratório Virtual Design (ViD) - integrado ao Programa de PósGraduação em Design da Universidade Federal do Rio Grande do Sul.

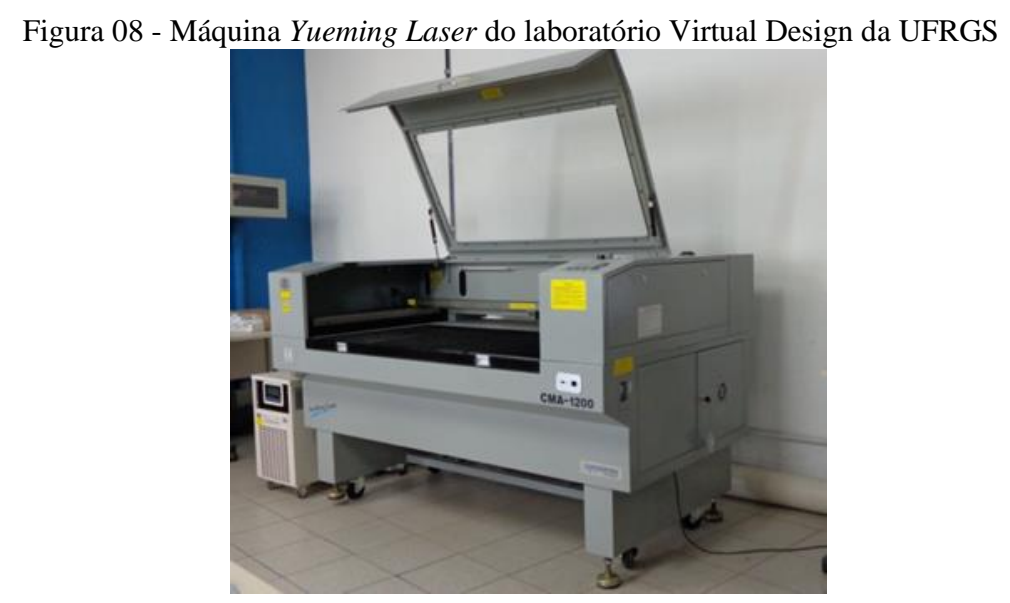

Fonte: acervo pessoal das autoras

Foram desenhados círculos de $12 \mathrm{~mm}$ para os testes (Figura 09). Manteve-se a velocidade de corte em $50 \mathrm{~mm} / \mathrm{s}$ e as potências foram variadas até atingir o número mais aproximado do ideal. Depois de oito variações de potência testadas, chegou-se aos seguintes números: potência mínima $-13 \%$; Potência máxima $-18 \%$. Vale salientar que os parâmetros de corte variam de acordo com a máquina a ser utilizada e com a espessura do couro. 


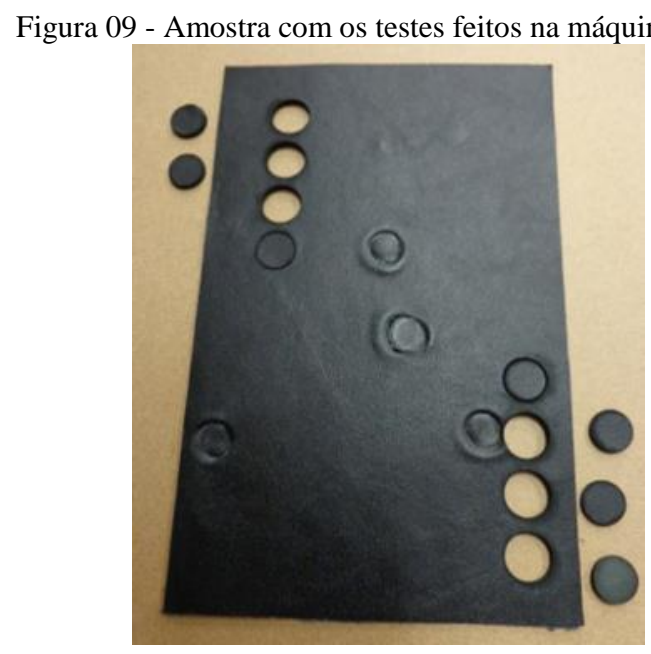

Fonte: acervo pessoal das autoras

\section{$3^{a}$ etapa | Montagem da marchetaria}

Todos os moldes chegam ao atelier em envelopes separados por cor e referência (Figura 10). Os moldes são conferidos; começa-se a montagem do desenho da marchetaria. Um gabarito em papel com os desenhos e as cores dos moldes auxilia a montagem. Os pequenos pedaços de couro são colados individualmente com cola de contato em um processo minucioso para que não haja desníveis na superfície e diferenças entre um encaixe e outro.

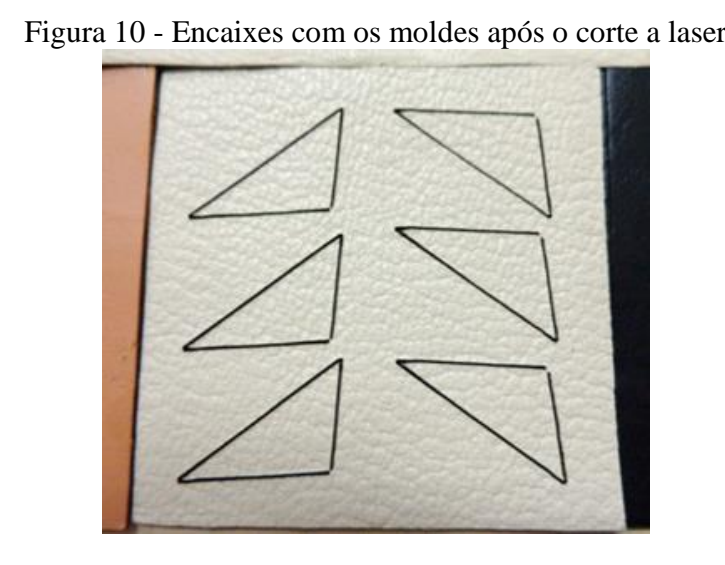

Fonte: material cedido pela marca Brantê

\section{$4^{\mathrm{a}}$ etapa $\mid$ Montagem das peças}

Nessa etapa, as bases marchetadas em couro são organizadas, assim como metalurgia que será aplicada a cada acessório, para que as peças sejam montadas. 


\section{$5^{\mathbf{a}}$ etapa | Finalização}

No final do processo, os acessórios são revisados e as tags e etiquetas são adicionadas às peças. A Figura 11 apresenta produtos desenvolvidos e comercializados pela marca Brantê, nos quais pode-se perceber o processo produtivo baseado na marchetaria em couro

Figura 11 - Produtos desenvolvidos pela marca Brantê

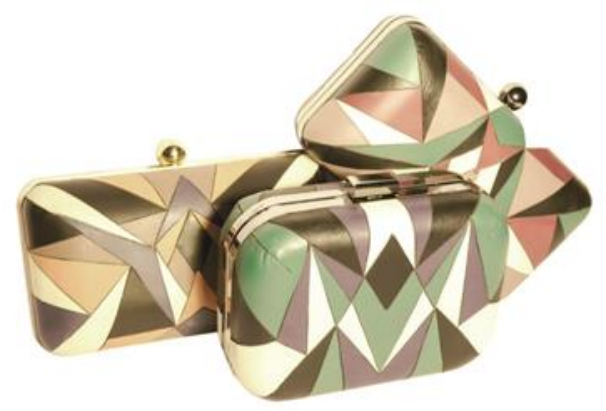

Fonte: material cedido pela marca Brantê

\section{CONSIDERAÇÕES FINAIS}

A marchetaria em couro mostrou-se um processo que ainda pode ser muito explorado, tanto em relação às técnicas empregadas quanto aos desenhos que podem ser desenvolvidos e aplicados ao couro. Formas geométricas são mais facilmente trabalhadas dentro do processo, porém acredita-se que os resultados serão semelhantes em desenhos cujas formas são mais orgânicas. Recomenda-se a realização de testes para confirmar os resultados em desenhos que utilizem formas orgânicas.

A utilização dos rejeitos de couro não afetou as características estéticas e a qualidade dos produtos finais desenvolvidos pela empresa analisada. Faz-se importante o desenvolvimento de processos que reaproveitem e reutilizem materiais que são descartados pela indústria. Como se viu, o design e um processo experimental de criação possibilitam a obtenção de resultados satisfatórios.

No entanto, é fundamental observar que o acabamento do produto depende diretamente da escolha das áreas do material. Por se tratar de um produto que já passou por um processo de seleção por outras empresas anteriormente e foi descartado, é importante que esse material passe por uma seleção cuidadosa sobre quais partes da peça de couro devem ser utilizadas. A finalidade é que o material que compõe o produto 
final transpareça ser de alta qualidade.

Através deste estudo de caso, também foi constatado que o resultado tido pela Brantê obtém êxito no mercado porque os produtos são desenvolvidos segundo um processo criterioso de design em que a atenção é voltada para todas as etapas do processo. Como resultado desse processo, é fundamental que os produtos apresentem acabamento final refinado, visto que se trata de produtos nos quais as funções estéticas e simbólicas são prioritárias. Dessa forma, constatou-se que, seguindo um padrão de qualidade em processos de design, é possível obter produtos refinados com o uso da marchetaria em couro.

A tecnologia de corte a laser, tanto torna o acabamento melhor, quanto auxilia no desempenho do processo produtivo. Além dos materiais, outros fatores podem influenciar na natureza dos resultados, como a precisão do corte de acordo com o desenho. O processo é passível de ser aplicado em outros produtos, como móveis, produtos de decoração, além de outros produtos de moda, desde que sejam utilizados padrões adequados para o produto que será desenvolvido.

Artigo recebido em Julho de 2015. Aprovado em Setembro de 2015

DOI:http://dx.doi.org/105965/1982615x08172016268

\section{REFERÊNCIAS}

Associação Brasileira de Normas Técnicas (ABNT). NBR 10.004: Resíduos Sólidos Classificação. Rio de Janeiro, 2004.

BARTZ, A.; SILVA, D.; FIGUEIREDO, T.; SPOHR, C.Processo de corte em máquinas laser. SIEF -Semana Internacional das Engenharias da FAHOR, 2011. Disponível em: <www.fahor.com.br>. Acesso em: 12 mai. 2013.

CAMPOS H. S. AIndústria de Couros no Brasil - FEE. 2006. Disponível em: <revistas.fee.tche.br>. Acesso em: 28 jun. 2013. 
CASTILHOS, D.; TEDESCO, M.; VIDOR, C. Rendimentos de culturas e alterações químicas do solo tratado com resíduos de curtume e cromio hexavalente. Revista Brasileira de Ciência do Solo, Viçosa, v. 26, p. 1083-1092, 2002.

CIDADE, M. K. Caracterização e padronização do processo de gravação a laser em ágata aplicado ao design de joias. Dissertação (Mestrado em Design) - Programa de Pós-graduação em Design, Universidade Federal do Rio Grande do Sul, Porto Alegre, 2012.

COSTA, C.; CASTILHOS, D.; CASTILHOS, R.; KONRAD, E.; PASSIANOTO, C.; RODRIGUES, C. Efeito de adição de lodo de curtume sobres alterações químicas do solo, rendimento de matéria seca e absorção de nutrientes em soja. Revista Brasileira de Agrociência, Pelotas, v. 7, p. 189-191, 2001.

GUTTERRES, M.; OSÓRIO, T. MétodosAnalíticos Especiais Aplicados ao Couro. 2004. Disponível em: <www.aaqtic.org.ar>. Acesso em: 01 jul. 2013.

HU, J.; XIAO, Z.; ZHOU, R.; DENG, W.; WANG, M.; MA, S. Ecological Utilization of Leather Tannery Waste with Circular Economy Model.Journal of Cleaner Production. Vol. 19, 221 - 228, 2011.

LAGO, R. O Perigo é Azul. 2007. Disponível em: www.ufmg.br. Acesso em: 11 jun. 2013.

MANZINI, E.; VEZZOLI, C. O Desenvolvimento de Produtos Sustentáveis: os requisitos ambientais dos produtos industriais. $1^{\mathrm{a}}$ ed. $2^{\mathrm{a}}$ reimpr. São Paulo: Editora da Universidade de São Paulo, 2008.

MATOS, P.; LOPES, Q.; NARDI, A.; OROFINO, G.; PIRES, S.; BICCA, D.

Considerando mais o lixo. Florianópolis: Insular, 1999.

Ministério do Desenvolvimento, Indústria e Comércio Exterior Brasileiro. Couros e Calçados. Disponível em: <www.desenvolvimento.gov.br>. Acesso: 05 jul. 2013.

PACHECO, J. CURTUME - Série P+L. 2005. Disponível em: <www.cetesb.sp.gov.br>. Acesso em: 27 jun. 2013. 
RASEIRA, C.Design e tecnologia aplicados a resíduos de madeira: Caracterização do processo de corte a laser para marchetaria. Dissertação (Mestrado em Design) Programa de Pós-graduação em Design, Universidade Federal do Rio Grande do Sul, Porto Alegre, 2013.

SMITH, Q. An Introduction to Marchetry. American Marchetry Society - Couse, 2002. Disponívelem: <www.americanmarquetrysociety.com>. Acesso em: 05 jul. 2013. STÜRMER, P. Materiais naturais: design e tecnologia no desenvolvimento de joias inspiradas na cultura gaúcha. Dissertação (Mestrado em Design) - Programa de Pósgraduação em Design, Universidade Federal do Rio Grande do Sul, Porto Alegre, 2010.

SUDHA, T.; THANIKAIVELAN, P.; AARON, K.; KRISHNARAJ, K;

CHANDRASEKARAN, B. Comfort, Chemical, Mechanical, and Structural Properties of Natural and Synthetic Leathers Used for Apparel. Journal of Applied Polymer Science. Vol. 114, 1761-1767, 2009.

VAZ, H.; SILVA, L.; MARTINS, M; MODESTO JUNIOR, O. Aproveitamento dos Resíduos de Couros Curtidos com Cromo: Resíduos da Rebaixadeira. 2009.

Disponível em: <www.unisalesiano.edu.br>. Acesso em: 27 jun. 2013. 